\title{
DESENVOLVIMENTO DE CURSOS DE APERFEIÇOAMENTO PROFISSIONAL A DISTÂNCIA NA ÁREA DO VESTUÁRIO PARA ATENDER REQUISITOS DA INDUSTRIA 4.0
}

\author{
GOIÂNIA /GO AGOSTO/2018
}

\author{
Kamilla Ramos e Silva - SENAI - kamilla.senai@sistemafieg.org.br \\ Tipo: Relato de Experiência Inovadora (EI) \\ Categoria: Métodos e Tecnologias \\ Setor Educacional: EDUCAÇÃO MÉDIA E TECNOLÓGICA
}

\begin{abstract}
RESUMO
Vivemos num sistema globalizado em que a forma de consumo e produção industrial vem se modificando. A moda convencional é um dos setores que mais causa efeitos ambientais negativos. Segundo Boriello (2017) para alguns setores, como o têxtil e o de confecção, já começou a quarta revolução industrial, ou indústria 4.0 na qual produzir de forma sustentável é um dos pilares. Realizado por meio das ditas tecnologias limpas este conceito requer a formação da mão de obra qualificada dentro dos pilares sustentáveis. Surgindo a necessidade de cursos de aperfeiçoamento profissional à distância na área do vestuário.
\end{abstract}

Palavras-chave: Palavras chaves: educação a distância, aperfeiçoamento profissional, indústria 4.0. 


\section{INTRODUÇÃO}

Vivemos num sistema globalizado em que a forma de consumo e produção industrial vem se modificando aos olhos dos ideais sustentáveis. Segundo estudiosos, para que futuras gerações possam viver uma transição do antropocentrismo para o biocentrismo e desfrutar das riquezas naturais do nosso planeta faz se necessário que a indústria e a sociedade mudem sua forma de consumir e produzir.

A moda convencional é um dos setores que mais causa efeitos ambientais negativos. Segundo Boriello (2017) para alguns setores, como o têxtil e o de confecção, já começou a quarta revolução industrial, ou indústria 4.0 na qual produzir de forma sustentável é um dos grandes pilares. Essa transição percebe a escassez e degradação dos recursos naturais e impulsiona o uso das ditas tecnologias limpas e menos poluentes e sistemas de produção que pensem todo o ciclo de vida dos produtos antes de eles serem produzidos.

O verdadeiro desafio é repensar e redefinir a forma de desenhar, produzir distribuir e utilizar as peças. Sendo que para ter um produto sustentável este deverá ser pensado do inicio ao fim se espelhando no ciclo de vida da natureza. Estes conceitos já fazem parte do sistema, hoje os consumidores usam o seu poder de compra a favor de causas sociais e ambientais logo a manufatura limpa ganha cada vez mais espaço.

Esta manufatura tem como ideal a diminuição do desperdício, e para isso novas técnicas de desenvolvimento sujem em meio à necessidade da qualificação de mão de obra qualificada. $O$ desenvolvimento de cursos de aperfeiçoamento unidos a Educação a Distância $(\mathrm{EaD})$ parece ser o resultado da trajetória da industria 4.0.

É notório o potencial da educação a distância na qual diante das possibilidades virtuais a prática tem garantia de eficácia. O crescente número de usuários do $(\mathrm{EaD})$ faz parte dos pilares de virtualização desta $4^{\circ}$ revolução industrial.

Os cursos "Modelagem Customização em Larga Escala" (EaD) e "Modelagem Zero Waste" (EaD), ofertados na modalidade a distância, voltados para a indústria, se tornam possível pela criação de customizações padronizadas.

\section{OBJETIVO}

Desenvolver curso com técnicas de modelagem sustentável e planejar ações para que na educação a distância $(\mathrm{EaD})$ esta pratica seja aprendida com eficácia. Além do foco 
em teorizar sobre sustentabilidade, conceituando o novo reposicionamento dos hábitos de consumo de moda; descobrir os fatores voltados para o ensino com conceitos e praticas eficazes nos cursos: Modelagem Customização em Larga escala (EaD) e Modelagem Zero Waste (EaD).

\section{REFERENCIAL TEÓRICO}

A indústria da moda é uma das maiores do mundo, segundo a ABIT - Associação Brasileira da Indústria Têxtil e de Confecção é a segunda maior empregadora da indústria de transformação, perdendo apenas para alimentos e bebidas. Só o Brasil em de 2017 no varejo de Vestuário produziu 6,71 bilhões de peças, contra 6,3 bilhões de peças em 2016. A tendência de uma moda com renovação constante das peças de roupa no varejo de moda - Fast fashion - colaborou e muito pra isso.

Esta forma de produção e consumo acelera intensifica a degradação do mundo. Mas, como a vida é feita em ciclos surge em contrapartida novas propostas pela moda afim de uma maior conscientização e produção mais sustentável. Segundo Salcedo (2014) o novo paradigma do sec. XXI é a sustentabilidade.

Salcedo (2014) ressalta que sustentabilidade não é algo agregado e sim parte do processo, a autora traz várias técnicas na produção do vestuário que minimizam as sobras e visam à reutilização de resíduos, durante o processo de produção de roupas, uma dessas técnicas é a modelagem Zero Waste - alternativa de modelagem mais limpa e a customização de roupas.

Alison Gwilt (2014) ressalta que evitar o desperdício por meio de uma montagem eficiente desempenhou um papel importante na produção de peças nos tempos antigos, porém quando a moda tornou-se mais justa ao corpo era preciso que as roupas tivessem um formato com modelagens cheias de retas e curvas e os moldes passaram a não se encaixar, gerando sobras de tecido e desperdício.

Segundo dado SINDITÊXTIL-SP (2017) só a região do Bom Retiro, em São Paulo (SP), 1200 confecções produzem 20 toneladas de resíduos têxteis por dia, considerando que em uma confecção a parte de corte e modelagem é a que mais gera desperdício no segmento do vestuário, o encaixe da matriz ocasiona vários espaços entre as peças onde os moldes não conseguem fazer um encaixe perfeito sem sobras, apesar de existir já software que consegue minimizar estes encaixes chegando a um desperdício mínimo de 10 a $20 \%$, ainda se tem uma sobra grande diante do número de confecção que temos no mundo, sobras que acabam sendo destinada aos aterros sanitários, e 
contribuindo com a poluição mundial.

Dentro da produção do vestuário a modelagem das roupas é uma das etapas que pode evitar a sobra de tecido com o uso de técnicas que desenvolvam peças que se encaixem melhor.

\section{CURSOS DE APERFEIÇOAMENTO EaD - MODELAGEM PLANA - ZERO WASTE e MODELAGEM CUSTOMIZAÇÃO EM LARGA ESCALA}

Existem vários cursos de modelagem com varias técnicas para o desenvolvimento de roupas. Porem, a maioria desses cursos são desenvolvidos em função da moda convencional. Logo, o desenvolvimento de um curso de modelagem que seja direcionado a moda mais sustentável se faz necessário num período em que a moda precisa ser pensada e desenvolvida com propósito. Em seu livro Moda com propósito Carvalhal (2016) ressalta que o mundo antropocêntrico baseado no eu e na competição está em choque com outro no qual a colaboração e empatia pedem passagem.

Os cursos de aperfeiçoamento são desenvolvidos a fim de agregar ao conhecimento já existente novas técnicas isso, vem a calhar, pois quem produz moda convencional pode ser instigado a transformar o olhar e propor mudanças, adquirir conhecimentos voltados ao desenvolvimento da modelagem Zero Waste e customizada, um mundo de possibilidades sustentáveis se abrem.

Estas técnicas podem ser desenvolvidas por meio da moulage, modelagem tridimensional e também pela modelagem bidimensional, ou ainda pela mistura das duas. O programa do curso foi desenvolvido com técnicas da modelagem plana, visto que esta é a mais utilizada pela indústria.

As competências do curso foram pensadas visando a implantação de uma modelagem plana básica intermediaria do traçado do vestido neste primeiro momento, tentando causar similaridade ao que já é feito nos cursos presenciais de aperfeiçoamento porem com formas particulares que remetam ao ensino a distância. A gravação de videoaula, apostilas, imagens, conteúdos previamente preparados, web aulas e fóruns em que possam ser conduzidas as situações de aprendizagens.

\section{PROCEDIMENTOS METODOLÓGICOS}

A modelagem plana industrial possui muitas curvas e partes que muitas das vezes se completam somente ao serem costuradas. E além disso sabe-se hoje que o infesto bem 
feito e bem programado minimiza as sobras de tecido, softwares calculam e executam 0 encaixe das peças em uma matriz que conseguem utilizar até $80 \%$ do tecido, sendo assim o desafio de zero resíduo se torna maior ainda.

Os aspectos estéticos destas peças contam com a aceitação de consumidores que já sabem de suas responsabilidades perante o planeta e tem um olhar diferenciado e ainda a quem tenha um olhar critico ao que é imposto como belo pelo mercado em massa, e instigar o olhar acostumado.

As competências do curso foram pensadas visando a implantação de uma modelagem plana básica intermediária do traçado do vestido neste primeiro momento, tentando causar similaridade ao que já é feito nos cursos de modelagem porém com formas diferentes que remetam ao não desperdício.

A modelagem plana é desenvolvida e ensinada por meio de diagramas geometrizados que ao serem desenvolvidos formam peças de roupas, a metodologia do curso aqui proposto será feita por estes diagramas, sendo que estes ao serem concluídos terão formas que se encaixem a fim de reduzir o desperdício têxtil, como já foi dito anteriormente ser a característica da modelagem Zero Waste.

Molde básico é um molde traçado para servir de apoio, ponto de partida para modelar diferentes modelos. Como faremos um molde básico voltado para modelagem sem resíduo poderemos chamá-lo de molde básico intermediário, pois de acordo com Aldrich (2014) estes podem ser desenvolvidos para modelos específicos. O uso da educação a distância, mediada via Internet será feito da somatória de conteúdo escrito e vídeoaulas favorecendo aprendizagem desta prática.

$\mathrm{Na}$ imagem abaixo um exemplo diagrama que pode ser trabalhado no desenvolvimento destas técnicas:

Figura 1 - diagrama sustentável

Este é um exemplo de modelo básico que pode ser trabalhado nos curso de 
aperfeiçoamento proposto, ao contrário da maioria dos moldes básicos que segundo Brandão (6ํㅡ. Ed.) são traçados pela $4^{\circ}$ parte, foi construído para obter o molde por inteiro, levando em conta não só as medidas de contorno e altura do corpo, mas também a largura do tecido.

A medida de largura de ombro a ombro é usada como medida de contorno em todas as alturas, as medidas de altura permanecem as convencionais. Esta medida de ombro a ombro é dividida pela largura do tecido a fim de se saber a quantidade de peças podem ser cortadas no fio reto com ângulo de $90^{\circ}$ no tecido. Exemplo: 1.20 de largura de tecido dividido por $38 \mathrm{~cm}$ de ombro a ombro (largura) mais $2 \mathrm{~cm}$ da faixa da cintura $(1.20 / 40=$ 3). Seria possível cortar três vestidos básicos intermediários. Sendo que na altura ou metragem do tecido é possível gerar emendas para evitar sobras.

Sabe-se que para verificar o resultado da modelagem é necessário ser feito a uma peça piloto, a fim de se verificar movimentos, caimento e beleza. Assim, esta será um requisito que o aluno deverá desenvolver para a conclusão do curso. A possibilidade de envio de imagens via internet e a porcentagem de momento presencial do ensino a distância garante a verificação das peças de roupas desenvolvidas.

\begin{tabular}{|l|l|l|}
\hline Etapas & Benefícios & Aspectos econômicos \\
\hline $\begin{array}{l}\text { Diagrama da Modelagem } \\
\text { Básica do Vestido }\end{array}$ & $\begin{array}{l}\text { Diminuição dos resíduos } \\
\text { têxteis }\end{array}$ & $\begin{array}{l}\text { Maior aproveitamento no } \\
\text { tecido gerando mais } \\
\text { lucro. }\end{array}$ \\
\hline Confecção de peça piloto. & $\begin{array}{l}\text { Verificação dos } \\
\text { movimentos, caimento e } \\
\text { beleza das peças. }\end{array}$ & $\begin{array}{l}\text { Peças bonitas e } \\
\text { confortáveis vendem mais } \\
\text { e geram lucro. }\end{array}$ \\
\hline $\begin{array}{l}\text { Desenvolvimento de } \\
\text { diagrama sustentável pelo } \\
\text { próprio aluno. }\end{array}$ & $\begin{array}{l}\text { Estimular novas formas de } \\
\text { construção. }\end{array}$ & $\begin{array}{l}\text { Peças bonitas e } \\
\text { confortáveis vendem mais } \\
\text { e geram lucro. }\end{array}$ \\
\hline
\end{tabular}


Figura 2 - Conteúdo programado e analise de proposta

\section{DISCUSSÃO DOS RESULTADOS}

O desenvolvimento do presente estudo analisou a possibilidade do uso da técnica Zero Waste no desenvolvimento do curso de aperfeiçoamento em modelagem plana a fim de repensar as técnicas de criação desde o inicio do desenvolvimento de um produto. $A$ pretensão aqui é saber se esta técnica pode ser sistematizada assim como as convencionais já são feitas, e promover esta técnica que visa reduzir o desperdício de tecido.

Usamos os conceitos sustentáveis, a modelagem plana convencional para o desenvolvimento de molde básico intermediário mais consciente. O resultado foi roupa geometrizada que possibilita o uso completo do tecido e que podem ser adaptadas a mais de um tipo físico.

Percebemos que o estudo de outros elementos se faz necessário para o sucesso e a eficácia do processo sustentável no desenvolvimento das roupas. Exemplos são: a familiaridade com o tecido e os materiais que são feitos, os aviamentos, aonde e como as peças serão vendidas, aceitação, comportamento, como serão descartadas, e ainda o desenvolvimento de modelagens mais elaboradas e criativas.

O estudo percebeu que a sistematização da modelagem - Zero Waste é possível e ajudará nessa caminhada sustentável do século XXI.

\section{CONSIDERAÇÕES FINAIS}

O desenvolvimento do presente estudo analisou a possibilidade do uso do ensino a distância a pretensão é saber se esta técnica pode ser sistematizada assim como as convencionais já são feitas, e promover esta técnica que visa reduzir o desperdício de tecido - O ensino da Modelagem Zero Waste voltados para a indústria e a modelagem 
por customizações.

O estudo percebeu que o ensino a distância é uma ótima opção para o desenvolvimento da sistematização da modelagem - Zero Waste e modelagem customizada. Pois esta modalidade que depende muito da prática pode ser ensinada e aprendida na comunicação de dupla via - EAD - permitindo a interação por meio de vídeo, arquivos e imagens. Esta interação comparada a presencial tem grande eficácia pois a possível revisitação aos vídeos explicativos e materiais de estudo permite um melhor estudo. Visto que em sala de aula nos dias de hoje os alunos muitas das vezes pedem ao professor pra poderem gravar uma aula pratica.

\section{REFERÊNCIAS}

BRANDÃO, Gil. Aprenda a Costurar. Ediouro.6ํㅡ.

SAGESSE,SILVIA e DUARTE, SONIA. Modelagem Industrial Brasileira. Rio de janeiro, $4^{\circ}$ Ed., 2018.

BRAUNGART, Michael e MCDONOUGH, William. Cradle to cradle: Criar e reciclar ilimitadamente. São Paulo, $1^{\circ}$ Ed., Editora G Gili, 2013.

SALCEDO, Helena. Moda ética para um futuro sustentável. Barcelona, Editora Gustavo Gili, 2014.

GWILT,ALISON. Moda sustentável: um guia prático. São Paulo, Ed. $1^{\circ}$, Editora G Gili,2014.

ALDRICH, WINIFRED. Modelagem plana para moda feminina. Porto Alegre, $5^{\circ}$ ed.,editora Bookman,2014

CARVALHAL, ANDRÉ. Moda com propósito: manifesto pela grande virada. São Paulo, $1^{\circ}$ Ed. Editora Paralela, 2016.

Textos retirados/publicados na internet

http://www.sinditextilsp.org.br/noticias/sinditextil-sp-apresenta-retalho-fashion-para-anova-gestao-da-amlurb. 